\title{
Current state-of-the-art knowledge on the role of omega-3 fatty acids in the prevention of cardiovascular disease
}

\author{
Longina Kłosiewicz-Latoszek ${ }^{1, A-D, F} \oplus$, Barbara Cybulska ${ }^{1, C, F}{ }^{\oplus}$, Piotr Tyszko ${ }^{2, E-F \oplus}$ \\ ${ }^{1}$ National Institute of Public Health -National Institute of Hygiene, Warsaw, Poland \\ 2 Institute of Rural Health, Lublin, Poland \\ A - Research concept and design, B - Collection and/or assembly of data, C - Data analysis and interpretation, \\ $D$ - Writing the article, $E$ - Critical revision of the article, $F$ - Final approval of article
}

Kłosiewicz-Latoszek L, Cybulska B, Tyszko P. Current state-of-the-art knowledge on the role of omega-3 fatty acids in the prevention of cardiovascular disease. Ann Agric Environ Med. 2020; 27(4): 519-525. doi: 10.26444/aaem/126674

\begin{abstract}
Introduction. Polyunsaturated n-3 fatty acid preparations containing eicosapentaenoic acid (EPA) and docosahexanaenoic acid (DHA), or EPA only, have long been recommended in the management of hypertriglyceridaemia, especially when severe (triglyceride levels $\geq 500 \mathrm{mg} / \mathrm{dL}$ ), at the dose of $2-4 \mathrm{~g} / \mathrm{d}$, mostly for the prevention of acute pancreatitis.

Materials and method. The presented article reviews clinical trials and their metaanalyses which evaluated the effect of n-3 fatty acids on cardiovascular disease risk, and regulatory agencies' and cardiac societies' positions regarding their use. Results. The findings indicate that only EPA is effective. Particular clinical benefit ( $25 \%$ reduction of cardiovascular events) was observed in the recently published REDUCE-IT trial which evaluated EPA (icosapent ethyl) at the dose of $4 \mathrm{~g} / \mathrm{d}$ for 4.9 years (median), compared to placebo, in hypertriglycerydaemic patients at high or very high cardiovascular risk. This positive effect has been reflected in the expert opinions which recommend eicosapent ethyl $(4 \mathrm{~g} / \mathrm{d})$ in patients similar to those participating in the REDUCE-IT trial. Additional data in favour of the above position have been provided by the EVAPORATE trial results which showed reduced progression of coronary atherosclerosis with EPA at the dose of $4 \mathrm{~g} / \mathrm{d}$.

Conclusion. The clinical studies and metaanalyses strongly point out that only EPA (icosapent ethyl), especially at dose of $4 \mathrm{~g} / \mathrm{d}$, is effective in reducing cardiovascular events in very high and high risk patients with hypertriglyceridemia. The use of EPA + DHA preparations in doses up to $1 \mathrm{~g} / \mathrm{d}$ does not prevent recurrent cardiovascular events.
\end{abstract}

\section{Key words}

cardiovascular disease prevention, omega-3 fatty acids, mechanism of action, clinical trials, metaanalyses, EPA; indications

\section{INTRODUCTION}

The present review on the role of polyunsaturated omega-3 fatty acids in the prevention of cardiovascular disease was inspired by a recent publication on the positive results of the REDUCE-IT trial with highly purified eicosapentaenoic acid (EPA) ethyl ester (icosapent ethyl) in statin-treated, highrisk patients with atherosclerotic cardiovascular disease or diabetes mellitus and triglyceride (TG) level of 135-499 mg/ $\mathrm{dL}$ [1]. The results of this study have been highly rated by experts, as evidenced by their prompt incorporation in the guidelines on the management of dyslipidemia in patients, similar to those who benefited from this treatment in the REDUCE-IT study $[2,3,4,5,6]$.

Mechanism of action. Omega-3 fatty acids are long-chain polyunsaturated fatty acids (PUFA) which play a major role in cell functioning and are essential for the body $[7,8]$. The most important of them include eicosapentaenoic acid (EPA) and docosahexanaenoic acid (DHA). However, synthesis of EPA and DHA from alpha-linolenic acid (ALA) in the human body is limited $(<1 \%)$, and their major source are fatty marine fish, and fish oil supplements.

Address for correspondence: Longina Kłosiewicz-Latoszek, National Institute of Public Health - National Institute of Hygiene, Powsińska, 61/63, 02-903 Warsaw, Poland

E-mail: klosiewiczlongina@gmail.com

Received: 17.04.2020; accepted: 23.08.2020; first published: 07.09.2020
Omega-3 fatty acids are structurally and functionally important components of membrane phospholipids which affect cellular metabolism, signaling processes, and regulation of gene expression. Pleotropic properties of omega-3 fatty acids include their anti-inflammatory, antioxidant, cardioprotective, and anti-cancer effects $[8,9$, 10]. In addition, they affect normal prenatal development, maturation of the central nervous system, and development of cognitive and behavioural function, speech, and vision in infants and small children.

The cardioprotective effect of omega- 3 fatty acids is associated with improved lipoprotein metabolism, their antiinflammatory, antiarrhythmic and antithrombogenic effects, and blood pressure lowering $[9,11,12,13,14]$.

EPA and DHA lower serum TG level, and thus may be used in the treatment of hypertriglyceridaemia $[2,3,8,15]$. Even if low-density lipoprotein (LDL) cholesterol (LDL-C) level is well-controlled, an elevated TG level is associated with a residual risk of atherosclerotic cardiovascular disease $[16,17]$. A reduction in serum TG level by EPA and DHA is a result of reduced hepatic very low-density lipoprotein (VLDL) secretion $[3,18]$. Omega-3 fatty acids inhibit diacylglycerol acyltransferase, the main enzyme responsible for hepatic TG synthesis. Other mechanisms of actions include inhibiting phosphatidic acid phosphatase, the enzyme that controls intracellular diacylglycerol level, and reducing de novo lipogenesis by inhibiting sterol regulatory element binding protein-1c (SREBP) gene transcription [19]. In addition, 
omega-3 fatty acids induce intracelullar degradation of apolipoprotein B (apo B), which in combination with reduced TG synthesis, may lead to lower accumulation of VLDL particles in hepatocytes and reduced hepatic VLDL secretion [20]. Another potential mechanism of serum TG level reduction involves increased peripheral TG clearance and reduced hepatocyte fatty acid pool, which is a source for TG synthesis in hepatic cells [18].

Both EPA and DHA exert a similar TG-lowering effect, but differ in their effect on LDL-C and high-density lipoprotein (HDL) cholesterol (HDL-C) levels [9, 11, 12, 13]. DHA was shown to increase the LDL-C level and LDL particle size, and moderately increase the HDL-C level (mostly in HDL2), while EPA-only preparations significantly reduce the serum TG level without increasing the LDL-C level, and may insignificantly reduce the HDL-C level (mostly in HDL3) $[9,11,12,21]$.

The above differences in the effects on lipids and lipoproteins may be one explanation for varying clinical effects in studies using different preparations of omega-3 fatty acids $[3,22,23,24,25]$. The EPA and DHA content of most studied preparations for hypertriglyceridaemia treatment is shown in Table 1 [3].

Table 1. Composition of some omega-3 fatty acid preparations with EPA and DHA content

\begin{tabular}{lcc}
\hline Trade name (year) & EPA $(\mathrm{g})$ & DHA $(\mathrm{g})$ \\
\hline Epanova (2014) & 0.55 & 0.2 \\
Lovaza (2004) & 0.43 & 0.345 \\
Omtryg (2014) & 0.43 & 0.345 \\
Vascepa (2012) & 0.88 & 0 \\
Omacor (2004) & 0.46 & 0.380 \\
\hline
\end{tabular}

EPA and DHA content given for $1 \mathrm{~g}$ of capsule contents.

* Year of approval by the Food and Drug Administration (FDA).

The anti-arrhythmic effect of omega- 3 fatty acids has been related to stabilization of cardiomyocyte electrical activity [25]. Anti-thrombogenic properties have been related to reduced synthesis of thromboxane A2, a prostaglandin which mediates platelet aggregation and has a vasoconstricting effect [25]. EPA has been shown to reduce platelet adhesion and reactivity, which manifests with a prolonged bleeding time. A reduction in fibrinogen and an increase in tissue plasminogen activator level has also been observed, which may also contribute to the antithrombogenic effect of omega-3 fatty acids [25].

Omega-3 fatty acids, and in particular EPA, improve inflammation markers, including the EPA to arachidonic acid (AA) ratio, oxidized LDL (ox-LDL), lipoprotein-associated phospholipase A2 (Lp-LPA 2 ), adiponectin, interleukin (IL)-6, IL-10, monocyte chemoattractant proteins, and pentraxin-3 $[26,27]$. In statin-treated patients with hypertriglyceridaemia and elevated high-sensitivity C-reactive protein (hsCRP) level $(\geq 2.0 \mathrm{mg} / \mathrm{L})$, an addition of $4 \mathrm{~g} / \mathrm{d}$ of icosapent ethyl reduced hsCRP level $[26,27]$.

Omega-3 fatty acids improve endothelial function, including nitric oxide release $[25,27]$. It was shown that fish oil reduces free radical synthesis in neutrophils, which may have an effect on nitric oxide bioavailability. Improved endothelial function may also result from reduced endothelial expression of vascular cell adhesion molecules.

The above-mentioned effects may result in decreased plaque vulnerability and reduced formation of atherosclerotic plaques in experimental animals, and with reduced plaque progression or their regression in humans [28, 29, 30, 31]. This effect is mostly seen with EPA, which may partly explain the greater clinical benefits of EPA compared to DHA [29,31]. The EVAPORATE study, presented for the first time at the American Heart Association (AHA) Scientific Sessions (2019), showed that icosapent ethyl administered at a dose of $4 \mathrm{~g} / \mathrm{d}$ for 9 months in patients with TG level of 200-499 mg/dL, reduced progression of coronary atherosclerosis, as evaluated using multidetector computed tomography $[32,33]$.

The previously reported CHERRY study also showed that a combination of $1.8 \mathrm{~g} / \mathrm{d}$ of EPA and pitavastatin given for 6-8 months in patients with coronary artery disease, resulted in a significant $16.6 \%$ reduction of plaque volume compared to pitavastatin monotherapy [34]. The percentage of patients who experienced plaque regression was also significantly higher in the EPA/pitavastatin group, compared to the pitavastatin monotherapy group ( $50 \%$ vs $24 \%$ ). In that study, EPA had no effect on TG and cholesterol levels.

Clinical studies. Despite the above cardioprotective mechanisms of action of omega-3 fatty acids, the results of epidemiological and clinical studies of their supplementation are equivocal. The initial reports of a preventive effect of omega-3 fatty acids were published in 1970s [7,35]. These were observational studies performed in Alaska and Greenland among Inuits whose diet includes high amounts of omega-3 fatty acids consumed with fish and seal, showing that a high intake of omega-3 fatty acids was associated with a lower risk of cardiovascular disease, compared to the Danish population $[14,36]$. These findings were recently corroborated by Japanese authors who showed that among 1,270 healthy men $>50$ years of age, frequent fish consumption (6-7 times a week) was associated with a healthy lifestyle (less smoking, more frequent usual aerobic activity, longer sleep) and a reduced risk of ischaemic heart disease [37].

The GISSI-Prevenzione open trial, initially published in 1999, showed a significant reduction in the combined primary endpoint (death, non-fatal myocardial infarction, or stroke) in the omega- 3 fatty acid group (receiving $1 / \mathrm{g}$ of EPA + DHA as ethyl esthers in the 1:2 proportion), compared to the control group [38]. The study was performed in 11,324 patients who had suffered a myocardial infarction within $\leq 3$ months. The duration of follow-up was 3.5 years. All-cause mortality was reduced by $20 \%$ (relative risk [RR] $0.80,95 \%$ confidence interval [CI] 0.67-0.94), cardiovascular mortality by $30 \%$ (RR $0.70,95 \%$ CI $0.56-0.87$ ), and sudden death by $45 \%$ (RR 0.55, 95\% CI 0.40-0.76).

In contrast, EPA alone at the dose of $1.8 \mathrm{~g} / \mathrm{d}$ was used in the randomized JELIS trial published in 2007 [39]. This was a prospective randomized trial with a mean follow-up of 4.9 years that included 18,645 patients with hypercholesterolaemia (total cholesterol $\geq 6.5 \mathrm{mmol} / \mathrm{L}$ ) who were treated with a statin. Established cardiovascular disease was present in $20 \%$ of the patients. Statin (pravastatin $10 \mathrm{mg} / \mathrm{d}$ or simvastatin $5 \mathrm{mg} / \mathrm{d})$ plus EPA $(\mathrm{n}=9362)$ was compared to statin alone $(\mathrm{n}=9319)$. The mean baseline cholesterol level was $7.11 \mathrm{mmol} / \mathrm{L}(275 \mathrm{mg} / \mathrm{dL})$ and the median TG level $1.73 \mathrm{mmol} / \mathrm{L}$ (ca. $153 \mathrm{mg} / \mathrm{dL}$ ). Compared to statin alone, statin plus EPA treatment resulted in a significant (19\%) reduction in the risk of the major coronary primary composite endpoint (sudden cardiac death, fatal and non-fatal myocardial infarction or coronary artery bypass grafting) (2.8\% vs. $3.5 \%$, hazard ratio [HR] $0.81,95 \%$ CI $0.69-0.95, \mathrm{P}=0.011]$. 
In a Japanese randomized trial, early initiation of EPA treatment at 24 hours after a percutaneous coronary intervention in patients with an acute coronary syndrome, was shown to reduce the cardiovascular event rate [40]. The study included 241 patients and compared pitavastatin $2 \mathrm{mg} / \mathrm{d}$ plus purified EPA $1.8 \mathrm{~g} / \mathrm{d}$ in the intervention group versus statin alone in the control group. Baseline TG level was $117 \mathrm{mg} / \mathrm{dL}$ in the intervention group and $105 \mathrm{mg} / \mathrm{dL}$ in the control group. At one year, a reduction in the primary endpoint (including cardiovascular death, non-fatal myocardial infarction, nonfatal stroke and revascularization) rate was found in the intervention group, compared to the control group (HR 0.42; $95 \%$ CI 0.21-0.87, $\mathrm{P}=0.02)$. Cardiovascular deaths were also significantly reduced ( $0.8 \%$ vs. $4.2 \%, \mathrm{P}=0.04)$.

A breakthrough study that provided evidence in favour of omega-3 fatty acid supplementation, specifically with EPA, was the REDUCE-IT study [1], which included 8,179 statintreated high risk patients with atherosclerotic cardiovascular disease $(71 \%)$ or diabetes with additional risk factors (29\%), and had a TG level between $\geq 135 \mathrm{mg} / \mathrm{dL}$ and $<500 \mathrm{mg} / \mathrm{dL}$ (median $216 \mathrm{mg} / \mathrm{dL}$ ) and LDL-C level between $>40 \mathrm{mg} / \mathrm{dL}$ and $\leq 100 \mathrm{mg} / \mathrm{dL}$ (median $75 \mathrm{mg} / \mathrm{dL}$ ). During the follow-up (median 4.9 years), the patients received highly purified EPA ethyl ester (icosapent ethyl) at the dose of $2 \mathrm{~g}$ twice daily $(4 \mathrm{~g} / \mathrm{d})$ or placebo. The reduction in the primary endpoint in the EPA group compared to placebo was $25 \%$ (HR 0.75 , 95\% CI $0.68-$ $0.83 ; \mathrm{P}<0.001)$, and the reduction in the secondary endpoint was $26 \%$ (HR $0.74,95 \%$ CI $0.65-0.83$; $\mathrm{P}<0.001$ ). The primary endpoint included cardiovascular deaths, non-fatal myocardial infarctions, non-fatal strokes, coronary revascularizations, and unstable angina. The secondary endpoint included major cardiovascular events and deaths. Of note, the benefits were higher in patients with established cardiovascular disease, with a relative risk reduction of $35 \%$. In the high risk population without cardiovascular disease, the relative risk reduction was modest at $16 \%$ [41]. Thus, the REDUCE-IT study showed that using large doses of EPA supplementation is warranted in high cardiovascular risk patients with hypertriglyceridaemia.

The results of the REDUCE-IT trial led to the abovementioned EVAPORATE study which evaluated whether icosapent ethyl at the dose of $4 \mathrm{~g} / \mathrm{d}$ had an effect on the progression of coronary atherosclerosis, evaluated for the first time using coronary computed tomographic angiography (CCTA) [42]. The study included 67 patients with a more than $20 \%$ stenosis of one or more coronary arteries, LDL-C level of 40-115 mg/dL, and TG level of 135-499 mg/dL (similar to the REDUCE-IT study), who were treated with statins. At the 9-month interim analysis of icosapent ethyl treatment compared to placebo, there was no significant change in low attenuation plaque (LAP) between active and placebo groups (74\% vs. 94\%; $\mathrm{P}=0.469$ ). However, there was slowing of total non-calcified plaque (sum of LAP, fibrofatty, and fibrous plaque) ( $35 \%$ vs. $43 \% ; \mathrm{P}=0.010)$, total plaque (non-calcified + calcified plaque) $(15 \%$ vs. $26 \% ; \mathrm{P}=0.0004)$, fibrous plaque ( $17 \%$ vs. $40 \% ; \mathrm{P}=0.011$ ), and calcified plaque (-1\% vs. $9 \%$; $\mathrm{P}=0.001)$ after adjustment by baseline plaque, age, gender, diabetes, baseline TG level, and statin use. The results of the EVAPORATE study indicate the mechanisms of beneficial clinical effects of EPA in the REDUCE-IT and JELIS studies $[1,39]$.

Results of the STRENGTH study, in which a combined omega-3 fatty acid preparation (Epanova) was used at the dose of $4 \mathrm{~g} / \mathrm{d}$ in patients with high TG level and low HDL-C level, were expected to provide more data on the efficacy of omega-3 fatty acids in the prevention of cardiovascular disease. However, the study was terminated in January 2020 due to the low likelihood of clinical benefits [43]. However, other clinical studies, RESPECTA-EPA and OMEMI, are ongoing $[44,45]$. The first of these studies is testing EPA at the dose of $1.8 \mathrm{~g} / \mathrm{d}$ in patients with a history of coronary artery disease, and is expected to end in 2022 [23]. In the OMEMI study, EPA + DHA at $1.8 \mathrm{~g} / \mathrm{d}$ is being administered to patients after myocardial infarction and is expected to end in 2020 [23].

Examples of negative trials include the VITAL and ASCEND studies published in 2018 [46,47]. The VITAL study included 25,871 individuals (51\% women), mean age 67.1 years (men $\geq 50$ years, women $\geq 55$ years), and duration of follow-up - 5.3 years. This was a randomized, placebocontrolled trial that evaluated the effect of vitamin D3 (2000 IU/d) and omega-3 fatty acids (840 mg/d of EPA + DHA) on the primary prevention of cardiovascular disease and cancer. Compared to the placebo group, the use of omega-3 fatty acids was not associated with a significant reduction in the overall major cardiovascular event rate (myocardial infarction, stroke, or cardiovascular death: hazard ratio [HR] 0.92, 95\% CI 0.80-1.06; P=0.24). Secondary endpoint analysis showed a significant difference only for myocardial infarction (HR 0.72, 95\% CI 0.59-0.90) and all coronary events (HR 0.83, 95\% CI 0.71-0.97). The other evaluated endpoints (stroke, cardiovascular death, cancer death, allcause death) did not differ significantly [46]. The ASCEND study included 15,480 diabetic patients (age $\geq 40$ years) without ischaemic heart disease who received omega-3 fatty acids $(1 \mathrm{~g} / \mathrm{d})$ or placebo. The duration of study was 7.4 years. No differences were shown for the primary endpoint of major cardiovascular events (myocardial infarction, stroke, transient ischaemic attack, or cardiovascular death: RR 0.97, 95\% CI 0.97-1.08) and the secondary endpoint which included major cardiovascular events and revascularization (RR 1.0, 95\% CI 0.91-1.09). The authors concluded that compared to placebo, omega-3 fatty acid supplementation had no effect on the risk of vascular events in diabetic patients without cardiovascular disease [47].

The characteristics and main results of some clinical studies with omega 3 fatty acids are presented in Table 2 [1, 46-53], some of which have been described above in detail. The clinical trials have shown that EPA+DHA preparations in a daily dose of $1 \mathrm{~g} / \mathrm{d}$ seems to be ineffective in the prevention of cardiovascular events. Such an opinion was voiced by the European Medicines Agency (EMA) on Mar 29, 2019 regarding patients after myocardial infarction [54].

Metaanalyses. Several metaanalyses of controlled studies evaluating omega-3 fatty acids for the prevention of cardiovascular disease were published in 2015-2020 [55-61, $62]$. In the opinion of the authors of the current study, the three most recent are of particular value [61,63]. In a metaanalysis of 13 omega-3 fatty acid studies, Marston et al. (2019) evaluated the dose-response relation between EPA and DHA and the risk of cardiovascular events [60]. Overall omega-3 fatty acid doses ranged from $376-4,000 \mathrm{mg}$ per day (mean $1,355 \mathrm{mg}$, median 1,000 mg). EPA doses ranged from 226-4,000 mg per day (mean $944 \mathrm{mg}$, median $500 \mathrm{mg}$ ). DHA was evaluated in 11 studies using doses ranging from 0-950 mg per day (mean $411 \mathrm{mg}$, median $380 \mathrm{mg}$ ). It was shown that each increase 
Table 2. Selected clinical studies of EPA and DHA

\begin{tabular}{|c|c|c|c|c|c|c|c|}
\hline Authors & Study & Number of patients & Duration (years) & Prevention & DHA and/or EPA & Dose $(\mathrm{g} / \mathrm{d})$ & $\begin{array}{c}\text { Major vascular events } \\
\text { HR or OR }(95 \% \mathrm{Cl})\end{array}$ \\
\hline Marchioli et al. ${ }^{38}$ & GISSI -P & 11324 & 3.5 & $s / p$ & $\mathrm{DHA}+\mathrm{EPA}$ & 1.8 & $0.81(0.69-0.95)$ \\
\hline Yokoyama et al. ${ }^{39}$ & JELIS & 18645 & 4.9 & $s / p$ & EPA & 1 & $0.86(0.74-0.99)$ \\
\hline Rauch et al. ${ }^{47}$ & OMEGA & 3851 & 1 & $s$ & $\mathrm{DHA}+\mathrm{EPA}$ & 1 & $0.95(0.56-1.60)^{1}$ \\
\hline Einvik et al. ${ }^{48}$ & DOIT & 563 & 3 & $s / p$ & $\mathrm{DHA}+\mathrm{EPA}$ & 2.4 & $0.86(0.57-1.38)$ \\
\hline Bosch et al. ${ }^{49}$ & ORIGIN & 12536 & 7 & $s / p$ & $\mathrm{DHA}+\mathrm{EPA}$ & 1 & $1.01(0.93-1.10)$ \\
\hline Macchina et al. ${ }^{50}$ & FORWARD & 586 & 1 & $s / p$ & $\mathrm{DHA}+\mathrm{EPA}$ & 1 & $1.28(0.90-1.83)$ \\
\hline Bonds et al. ${ }^{52}$ & AREDS 2 & 4200 & 4.8 & $s / p$ & $\mathrm{DHA}+\mathrm{EPA}$ & 1 & $0.95(0.78-1.17)$ \\
\hline Nosaka et al..$^{40}$ & - & 241 & 1 & $s$ & EPA & 1.8 & $0.42(0.21-0.87)$ \\
\hline Bowman et. al. ${ }^{46}$ & ASCEND & 15480 & 7.4 & $\mathrm{p}$ & $\mathrm{DHA}+\mathrm{EPA}$ & 1 & $0.97(0.97-1.08)$ \\
\hline Manson et al. ${ }^{45}$ & VITAL & 25871 & 5.3 & $\mathrm{p}$ & $\mathrm{DHA}+\mathrm{EPA}$ & 1 & $0.92(0.80-1.06)$ \\
\hline Bhatt et al. ${ }^{1}$ & REDUCE-IT & 8179 & 4.9 & s & EPA & 4 & $0.75(0.68-0.83)$ \\
\hline
\end{tabular}

'Primary end point - sudden cardiac death

s, secondary; p, primary.

in EPA dose by $1 \mathrm{~g} / \mathrm{d}$ was associated with a significant $7 \%$ reduction in cardiovascular events (RR 0.93, 95\% CI 0.91-0.95). In contrast, each increase in DHA dose by $1 \mathrm{~g} / \mathrm{d}$ was associated with a non-significant $4 \%$ reduction in cardiovascular events (RR 0.96, 95\% CI 0.89-1.03).

Another notable recent comprehensive metaanalysis (2020) of 16 randomized trials of PUFA n-3 supplementation was performed by a study group that included world-renowned lipidology experts [61]. The metaanalysis included secondary prevention and combined secondary and high risk primary prevention studies. The intervention group included 40,611 patients and the control group included 40,462 patients. Studies with the duration of at least one year (1-6 years) in which the daily n-3 PUFA dose was at least $1.0 \mathrm{~g}(1.6-6.0 \mathrm{~g} / \mathrm{d})$ were included. EPA+DHA was used in 13 studies, and EPA only was used in 3 studies $[1,39,40]$. Patients with elevated TG levels participated in 6 trials.

No significant effect of PUFA n-3 supplementation on overall mortality was found (odds ratio [OR] 0.96, 95\% CI $0.88-1.04)$. A metaanalysis of 13 studies showed a significant $9 \%$ reduction in cardiac mortality (OR $0.91,95 \%$ CI $0.85-$ 0.98 ) in the intervention group compared to controls. No difference in non-cardiac mortality (12 studies) was observed between the 2 groups (OR 1.01, 95\% CI 0.94-1.04). Compared to placebo, PUFA n-3 supplementation was associated with significant reductions in major adverse cardiovascular event (MACE: fatal and non-fatal myocardial infarction, fatal and non-fatal stroke) and myocardial infarction rates, with the OR values of 0.90 (95\% CI 0.82-0.99) and 0.83 (95\% CI 0.71-0.98), respectively. These findings were obtained in the metaanalysis of all 16 studies. There was no difference (metaanalysis of 12 studies) in the rate of stroke (OR 1.0, 95\% CI 0.89-1.23).

A patient subgroup metaanalysis showed that a significant reduction in cardiac deaths occurred only in secondary prevention studies (OR 0.79, 95\% CI 0.67-0.93). In secondary prevention patients, a trend for a lower rate of MACE was observed, while this difference was significant in combined secondary and primary prevention studies. However, only the daily doses of $>1 \mathrm{~g}$ of n-3 PUFA were significantly effective at reducing cardiac deaths, MACE, and myocardial infarction. Compared to EPA+DHA supplementation, EPA supplementation was more effective at reducing MACE (OR 0.75, 95\% CI 0.63-0.82 vs. OR 0.96, 95\% CI 0.88-1.04) and myocardial infarction (OR $0.70,95 \%$ CI $0.60-0.81$ vs. OR $0.88,95 \%$ CI $0.74-1.04$ ), as evidenced by significant differences. The authors of the metaanalysis concluded that their results supported the guidelines of the European Society of Cardiology (ESC) and European Society of Atherosclerosis (EAS), as well as AHA and the Food and Drug Administration (FDA) recommendations regarding the use of large doses of icosapent ethyl in combination with a statin in patients at high or very high risk, and persisting mildly to moderately elevated TG levels $[2,3,62]$.

A network metaanalysis of 14 clinical trials with 125,763 participants was also published in 2020 which compared the effects of low ( $\leq 1 \mathrm{~g} / \mathrm{d}$; LD) and high ( $>1 \mathrm{~g} / \mathrm{d}$; HD) doses of $n-3$ fatty acids versus controls [63]. HD use was associated with a significantly lower risk of cardiac deaths (incidence risk ratio [IRR] 0.79, 95\% CI 0.65-0.96), myocardial infarction (IRR $0.71,95 \%$ CI 0.62-0.88), coronary revascularization (IRR 0.74, 95\% CI 0.66-0.85), unstable angina (IRR 0.73, 95\% CI 0.620.86 ), major vascular events (IRR $0.78,95 \%$ CI 0.71-0.85), compared to controls. Of note, HD was significantly better than LD with regard to myocardial infarction, coronary revascularization, unstable angina, and major vascular event rates. Thus, HD omega-3 fatty acid treatment was associated with a lower cardiovascular event risk compared to LD use. However, more bleeding episodes and atrial fibrillation events were noted in patients receiving $\mathrm{HD}$.

In summary, recent metaanalyses indicated that n-3 fatty acids doses $>1 \mathrm{~g} / \mathrm{d}$ are effective for the reduction of cardiovascular risk, with particular benefits of EPA $[61,63]$.

Adverse effects. Omega-3 fatty acid preparations are considered safe, but clinical studies indicate that adverse events including bleeding, arterial fibrillation, gastrointestinal upset, impaired glucose tolerance, and allergy may occur. The rate of omega-3 fatty acid preparation discontinuation has been estimated at $<5 \%[10]$.

In the REDUCE-IT study, the use of icosapent ethyl was associated with higher rates of bleeding and atrial fibrillation/ flutter compared to placebo [1]. Bleeding was noted in $11.8 \%$ of patients receiving icosapent ethyl vs. $9.9 \%$ of patients receiving placebo, and the rate of major bleeding was $2.7 \%$ vs. $2.1 \%$, respectively. The rate of fatal bleeding did not increase with the use of icosapent ethyl and was similar in both groups $(0.5 \%$ vs. $0.6 \%)$. An increase in the bleeding rate was noted in patients receiving anti-coagulants $(12.5 \%$ in the EPA group vs. $10.4 \%$ in the placebo group).

Atrial fibrillation/flutter requiring admission occurred in $3.1 \%$ patients receiving icosapent ethyl vs. $2.1 \%$ of patients receiving placebo. The increase in the rate of atrial 
fibrillation events was more pronounced in patients with atrial fibrillation at baseline $(12.5 \%$ in the EPA group vs. $6.3 \%$ in the placebo group). No increase in the stroke rate was observed, a common complication in subjects with atrial fibrillation.

Both the authors of the REDUCE-IT study and the FDA Advisory Committee members believe that the benefits of icosapent ethyl outweigh these adverse events, particularly in secondary prevention. The need to monitor patients for both atrial fibrillation and bleeding risk has been highlighted and appropriate information should be included in the drug label [3].

Gastrointestinal symptoms include fishy taste, belching, diarrhea, and nausea. These symptoms may be mitigated by taking these preparations with food [3]. Early studies also suggest a worsening of glucose control, as indicated in the metaanalysis of recent studies and other recent publications $[3,64,65]$. In the recent REDUCE-IT study, no increase in the haemoglobin Alc level and the rate of new-onset diabetes has been noted [1].

Although allergy has not been reported after administration of omega- 3 fatty acid preparations, the FDA suggests caution when using these preparations in patients allergic to fish and other seafood [57].

Indications for omega-3 fatty acids. The recommendations of the American and European societies are based on the results of clinical studies and their metaanalyses, and have been updated with advancing knowledge on this topic [2$5,66]$. Currently, omega-3 fatty acids are recommended in the management of hypertriglyceridaemia at the daily dose of 4 g/day (2019 ESC/EAS and AHA) [2, 3]. A daily omega-3 fatty acid dose of $4 \mathrm{~g}$ may reduce serum the TG level by $>30 \%$ in patients with TG levels $\geq 500 \mathrm{mg} / \mathrm{dl}$, and by $20-30 \%$ in patients with a TG level of $150-400 \mathrm{mg} / \mathrm{dl}$. In studies using EPA, even a $45 \%$ reduction in serum TG level was noted in subjects with high TG levels [2]. The FDA has approved 5 preparations for the management of severe hypertriglyceridaemia ( $\mathrm{TG} \geq 500 \mathrm{mg} / \mathrm{dL}$ ). These are both EPA + DHA preparations (Lovaza, Omtryg, Epanova, Omacor) and an EPA ethyl ester preparation (Vascepa) [3]. The composition of these products is given in Table 1 .

The EPA ethyl ester (at the dose of $2 \mathrm{~g}$ twice daily) has been recommended in the most recent 2019 ESC/EAS guidelines as a second-line drug after statins in high risk patients with hypertriglyceridaemia (TG 1.5-5.6 mmol/L [135-499 $\mathrm{mg} / \mathrm{dL}]$ ), replacing fenofibrate [2], which has now been relegated to third-line drug status. Clearly, this recommendation update has been affected by the REDUCEIT study results [1]. A similar statement has been published by the American Diabetes Association [6].

In December 2019, following publication of the REDUCEIT trial, the FDA approved EPA (icosapent ethyl; Vascepa) for the first time as an additional therapy to reduce the risk of cardiovascular events in patients with established cardiovascular disease or diabetes with two or more additional risk factors and TG level $\geq 150 \mathrm{mg} / \mathrm{dL}$. (62) EMA will finish its approval procedure by the end of 2020 [54].

Earlier, in 2013, Vascepa was approved by the FDA for the treatment of severe hypertriglyceridaemia (TG level $\geq 500 \mathrm{mg} / \mathrm{dL}$ ), similar to several other n-3 PUFA preparations (Lovaza, its generic version Omtryg, Epanova). The last 3 supplements contain EPA + DHA (Table 1).
Similar to the FDA approval and the 2019 ESC/EAS guidelines, based on the REDUCE-IT study results, the American National Lipid Association (NLA) has recommended the use of icosapent ethyl in patients $\geq 45$ years of age with established atherosclerotic cardiovascular disease, and in patients $\geq 50$ years of age with diabetes requiring drug treatment with $\geq 1$ additional risk factors, in whom the TG level during treatment with a maximum tolerated statin dose ( \pm ezetimibe) is $135-499 \mathrm{mg} / \mathrm{dL}$ [4].

\section{CONCLUSIONS}

Currently, combined EPA + DHA preparations or EPA alone at the daily dose of $4 \mathrm{~g}$ are recommended for the treatment of hypertriglyceridaemia, in addition to statin therapy. Following publication of the results of the REDUCE-IT study, a new indication for EPA (icosapent ethyl) in addition to the management of hypertriglyceridaemia is its use at the dose of $4 \mathrm{~g} / \mathrm{d}$ in patients with established cardiovascular disease or diabetes with $\geq 1$ risk factor to reduce cardiovascular event risk. This is the first such indication for $\mathrm{n}-3$ fatty acid, but only for EPA. Multiple n-3 fatty acid supplements are available in Poland; however, they are not always standardized in terms of the amount and purity of fatty acids. In addition, storage conditions may affect the quality of the preparation (due to oxidation of fatty acids). Thus, the FDA-approved preparations listed in Table 1, which are prescription drugs, are the most valuable in terms of effective reduction of the TG level. Omacor is available in Poland, approved as a medicinal product. However, only icosapent ethyl (Vascepa) at the dose of $4 \mathrm{~g} / \mathrm{d}$ should be used to reduce cardiovascular events in high and very high risk patients with hypertriglyceridaemia. This product is not yet available in Poland.

\section{REFERENCES}

1. Bhatt DL, Steg PG, Miller M, Brinton EA, Jacobson TA, Ketchum $\mathrm{SB}$, et al. Cardiovascular risk reduction with Icosapent ethyl for hypertriglyceridemia. N Engl J Med. 2019; 380: 11-22, doi: 10.1056/ NEJMoa1812792

2. Mach F, Baigent C, Catapano AL, Koskinas KC, Casula M, Badimon L, et al. 2019 ESC/EAS guidelines for the management of dyslipidaemias: lipid modification to reduce cardiovascular risk. Eur Heart J. 2020; 41: 111-188. doi: 10.1093/eurheartj/ehz455

3. Skulas-Ray AC, Wilson PWF, Harris WS, Brinton EA, Kris-Etherton PM, Richter CK, et al. Omega-3 fatty acids of the management of hypertriglyceridemia: A Science Advisory from the American Heart Association. Circulation 2019; 140: 12, e673-e691. doi: 10.1161/ CIR.0000000000000709

4. Orringer CE, Jacobson TA, Maki KC. National Lipid Association Scientific Statement on the use of icosapent ethyl in statin-treated patients with elevated triglycerides and high or very-high ASCUD risk. J Clin Lipidol. 2019; 13(6): 860-872. doi: 10.1016/j.jacl.2019.10.014 5. Siscovick DS, Barringer TA, Fretts AM, Wu JH, Lichtenstein AH, Costello, et al. Omega-3 polyunsaturated fatty acid (fish oil) supplementation and the prevention of clinical cardiovascular disease: A science advisory from the American Heart Association. Circulation 2017; 135: e867-e884. doi: 10.1161/CIR.0000000000000482

6. American Diabetes Association; 2019. https://www.diabetes.org/ newsroom/press-releases/2019/ada-issues-critical-updates-to-2019standards-of-care. Accessed September 19, 2019.

7. Zárate R, El Jaber-Vazdekis N, Tejera N, Perez JA, Rodriquez C. Significance of long chain polyunsaturated fatty acids in human health. Clin Transl Med. 2017; 6: 25. doi: 10.1186/s40169-017-0153-6

8. Watanabe Y, Tatsuno I. Prevention of cardiovascular events with omega-3 polyunsaturated fatty acids and the mechanizm involved. J Atheroscler Thromb. 2019; Oct 3. doi: 10.5551/jat.50658 
9. Mozaffarian D, Wu JH. Omega-3 fatty acids and cardiovascular disease: Effects on risk factors, molecular pathways, and clinical events. J Am Coll Cardiol. 2011; 58: 2047-2067. doi: 10.1016/j.jacc.2011.06.063

10. Mozaffarian D, Prineas RJ, Stein PK, Siscovick DS. Dietary fish and n-3 fatty acid intake and cardiac electrocardiographic parameters in humans. J Am Coll Cardiol. 2006; 38: 478-484.

11. Innes JK, Calder PC. The differential effects of eicosapentaenoic acid and docosahexaenoic acid on cardiometabolic risk factors: a systematic review. Int J Mol Sci. 2018; 19(2): 532. doi: 10.3390/ijms19020532

12. Jacobson TA, Glickstein SB, Rove JD, Soni PR. Effects of eicosapentaenoic acid and docosahexaenoic acid on low-density lipoprotein cholesterol and other lipids: a review. J Clin Lipid. 2012; 6: 5-18.

13. Wei MY, Jacobson TA. Effects of eicosapentaenoic acid versus docosahexaenoic acid on serum lipids: a systematic review and metaanalysis. Curr Atheroscler Rep. 2011; 13: 474-483. doi: 10.1007/s11883011-0210-3

14. Mozaffarian D, Wu JHY. (n-3) Fatty acids and cardiovascular health: are effects of EPA and DHA shared or a complementary? J Nutr. 2012; 142: 614S-625S

15. Musa-Veloso K, Binns MA, Kocenas AC, Poon T, Elliot JA, Rice $\mathrm{H}$, et al. Long-chain omega-3 fatty acids eicosapentaenoic acid and docosahexaenoic acid dose-dependentlyreduce fasting serum triglycerides. Nutr Rev. 2010; 68: 155-167. doi: 10.1111/j.17534887.2010.00272.x

16. Nordestgaard BG, Varbo A. Triglycerides and cardiovascular disease. Lancet. 2014; 384: 626-635. doi: 10.1016/S0140-6736(14)61177-6

17. Sampson UK, Fazio S, Linton MRF. Residual car-diovascular risk despite optimal LDL cholesterol reduc-tion with statins: The evidence, etiology, and therapeutic challenges. Curr Atheroscler Rep. 2012; 14: $1-10$.

18. Shearer GC, Savinova OV, Harris WS. Fish oil: how does it reduce plasma triglycerides? Biochim Biophys Acta. 2012; 1821: 843-851. doi: 0.1016/j.bbalip.2011.10.011

19. Kim CW, Addy C, Kusunoki J, Anderson NN, Deja S, Fu X, et al. Acetyl CoA carboxylase inhibition reduces hepatic steatosis but elevates plasma triglycerides in mice and humans: a bedside to bench investigation. Cell Metab. 2017; 26: 576. doi: 10.1016/j.cmet.2017.08.011

20. Pan M, Maitin V, Parathath S, Andreo U, Lin SX, St Germain C, et al. Presecretory oxidation, aggregation, and autophagic destruction of apoprotein-B: a pathway for late-stage quality control. Proc Natl Acad Sci USA. 2008; 105: 5862-5867. doi: 10.1073/pnas.0707460104

21. Vors C, Couture P, Lamarche B. Omega-3 fatty acids: new insights into the impact of eicosapentaenoic and docosahexaenoic acids on lipid and lipoprotein. Curr Opin Lipidol. 2020; 31: 38-39. doi: 10.1097/ MOL0000000000000660

22. Baum SJ, Scholz KP. Rounting the corner on residual risk: Implications of REDUCE-IT for omega-3 polyunsaturated fatty acids treatment in secondary prevention of atherosclerotic cardiovascular disease. Clin Cardiol. 2019; 42: 829-838. doi: 10.1002/clc. 23220

23. Jia X, Koh S, Al Rifai M, Blumenthal RS, Virani SS. Spotlight on icosapent ethyl for cardiovascular risk reduction: evidence to date Vasc Health Risk Manag. 2020; 16: 1-10. doi: 10.2147/VHRM.S210149

24. Harris WS. Understanding why REDUCE-IT was positive - mechanistic overview of eicosapentaenoic acid. Prog Cardiovasc Dis. 2019; 62: 401-405. doi: 10.1016/j.pcad.2019.10.008

25. Jain AP, Aggarwal KK, Zhang PY. Omega-3 fatty acids and cardiovascular disease. Eur Rev Med Pharmacol Sci. 2015; 19(3): 441-445.

26. Miller M, Ballantyne CM, Bays HE, Granowitz C, Doyle RT Jr, Juliano RA, et al. Effects of icocapent ethyl (eicosapentaenoic acid ethyl ester) on atherogenic lipid/lipoprotein, apolipoprotein, and inflammatory parameters in patients with elevated high-sensitivity C-Reactive Protein (from the ANCHOR Study). Am J Cardiol. 2019; 124(5): 696-701. doi: 10.1016/j.amjcard.2019.05.057

27. Brinton EA, Ballantyne CM, Bays HE, Kastelein JJ, Braeckman RA, Soni PN. Effects of icosapent ethyl on lipid and inflammatory parameters in patients with diabetes mellitus-2, residual elevated triglycerides (200-500 mg/dL), and on statin therapy at LDL-C goal: the ANCHOR study. Cardiovasc Diabetol. 2013; 12: 100. doi: 10.1186/1475-2840-12-100

28. Bays HE, Ballantyne CM, Braeckman RA, Stirtan WG, Soni PN. Icosapentethyl, a pure ethyl ester of eicosapentaenoic acid: effects on circulating markers of inflammation from the MARINE and ANCHOR studies. Am J Cardiovasc Drugs. 2013; 13: 37-46.

29. Nelson JR, True WS, Le V, et al. Can pleiotropic effects of eicosapentaenoic acid (EPA) impast residua cardiovascular risk? Postgrad Med. 2017; 129: 822-827. doi: 10.1080/00325481.2017.1385365

30. Boden WE, Bhatt DL, Toth PP, Ray KK, Chapman MJ, Lüscher TF, et al. Profound reductions in first and total cardiovascular events with icosapent ethyl in the REDUCE-IT trial: why these results usher in a new era in dyslpidaemia therapeutics. Eur Heart J. 2019; Dec 23. doi: 10.1093/eurheartj/ehz778

31. Nelson JR, Wani O, May HT, Budoff M. Potential benefits of eicosapentaenoic acid on atherosclerotic plaques. Vascul Pharmacol. 2017; 99: 1-9. doi: 10.1016/j.vph.2017.02.004

32. Budoff M, Muhlestein BJ, Le VT, et al. Effect of Vascepa (icosapent ethyl) on progression of coronary atherosclerosis in patients with elevated triglycerides $(200-499 \mathrm{mg} / \mathrm{dl})$ on statin therapy: rationale and design of the EVAPORATE Study. Clin Cardiol. 2018; 41: 13-19.

33. Budoff M, et al. AHA 2019

34. Watanabe T, Ando K, Daidoji H, Otaki Y, Sugawara S, Matsui M, et al. CHERRY Study Investigators. A randomized controlled trial of eicosapentenoic acid in patients with coronary heart disease on statins. J Cardiol. 2017; 70: 537-544.

35. DINIcolantonio JJ, O'Keefe JH. The benefits of Marine omega - 3s for the prevention and treatment of cardiovascular disease. Missouri Med. 2019; 116(5): 404-408.

36. Bang HO, Dyerberg J, Nielson AB. Plasma lipid and lipoprotein pat tern in Greenlandic West-coast Eskimos. Lancet 1971; 1: 1143-1145.

37. Tani S, Matsuo R, Imatake K, Suzuki Y, Takahashi A, Matsumoto N Association of daily fish intake with serum non-high-density lipoprotein cholesterol levels and healthy lifestyle behaviours in apparently healthy males over the age of 50 years in Japanese: Implication for the antiatherosclerotic effect of fish consumption. Nutr Metab Cardiovasc Dis. 2020 Feb 10; 30(2): 190-200. doi: 10.1016/j.numecd.2019.09.019

38. Marchioli R. Dietary supplementation with n-3 polyunsaturated fatty acids and vitamin E after myocardial infarction: Results of the GISSIPrevenzione trial. Lancet 1999; 354: 447-455.

39. Yokoyama M, Origasa H, Matsuzaki M, et al. Japan EPA lipid intervention study (JELIS) Investigators. Effects of eicosapentaenoic acid on major coronary events in hypercholesterolaemic patients (JELIS): a randomised openlabel, blinded endpoint analysis. Lancet 2007; 369: 1090-1098.

40. Nosaka K, Miyoshi T, Iwamoto M, Kajiya M, Okawa K, Tsukuda S, et al. Early initiation of eicosapentaenoic acid and statin treatment is associated with better clinical outcomesth an statin alone in patients with acute coronary syndromes: 1-year outcomes of a randomized controlled study. Int J Cardiol. 2017; 228: 173-9.

41. FDA Panel recommends high-dose EPA for CV event reduction. https:// www.medscape.com/viewarticle/921374

42. Budoff MJ, Muhlestein JB, Bhatt DL, Le Pa VT, May HT, et al. Effect of Icosapent Ethyl on Progression of Coronary Atherosclerosis in Patients with Elevated Triglycerides on Statin Therapy: A prospective, placebo-controlled randomized trial (EVAPORATE): Interim Results Cardiovasc Res. 2020 Jul 1: cvaa184. doi: 10.1093/cvr/cvaa184

43. Nicholls SJ, Lincoff AM, Bash D, Ballantyne CM, Barter PJ, Davidson MH SJ, et al. Assessment of omega-3carboxylic acids in statin-treated patients with high levels of triglycerides and low levels of high-density lipoprotein cholesterol: rationaleand design of the STRENGTH trial. Clin Cardiol. 2018; 41(10): 1281-1288. doi: 10.1002/clc. 23055

44. UMIN-CTR Clinical Trial. Randomized trial for evaluation in secondary prevention efficacy of combination therapy - statin and eicosapentaenoic acid UMIN000012069; 2018. Available from:https://upload.umin.ac.jp/cgi-open-bin/ctr_e/ctr_view. cgi?recptno=R000014051. Accessed November 22, 2019.

45. Laake K, Myhre P, Nordby LM, et al. Effects of $\omega 3$ supplementation in elderly patients with acute myocardial infarction: design of a prospective randomized placebo controlled study. BMC Geriatr. 2014; 14: 74. doi: 10.1186/1471-2318-14-74r

46. Manson JE, Cook NR, Lee IM, Christen W, Bassuk SS, Mora S, et al. Marine n-3 fatty acids and prevention of cardiovascular disease and cancer. N Engl J Med. 2019; 380: 23-32. doi: 10.1056/NEJMoa1811403

47. The Ascend Study Collaborative Group. Effects of n-3 fatty acid supplements in diabetes mellitus. N Engl J Med. 2018; 379(16): 1540 1550

48. Rauch B, Schiele R, Schneider S, Diller F, Victor N, Gohlke H, et al. OMEGA, a randomized, placebo-controlled trial to test the effect of highly purified omega-3 fatty acids on top of modern guideline-adjusted therapy after myocardial infarction. Circulation. 2010; 122: 2152-9.

49. .Einvik G, Ole Klemsdal T, Sandvik L, Hjerkinn EM. A randomized clinical trial on n-3 polyunsaturated fatty acids supplementation and all-cause mortality in elderly men at high cardiovascular risk. Eur J Prev Cardiol. 2010; 17: 588-92.

50. ORIGIN Trial Investigators, Bosch J, Gerstein HC, Dagenais GR, Díaz $\mathrm{R}$, Dyal L, et al. n-3 fatty acids and cardiovascular outcomes in patients with dysglycemia. N Engl J Med. 2012; 367: 309-18. 
51. Macchia A, Grancelli H, Varini S, Nul D, Laffaye N, Mariani J, et al. Omega-3 fatty acids for the prevention of recurrent symptomatic atrial fibrillation: results of the FORWARD (Randomized Trial to Assess Efficacy of PUFA for the Maintenance of Sinus Rhythm in Persistent Atrial Fibrillation) trial J Am Coll Cardiol. 2013 Jan 29; 61(4): 463-468. doi: 10.1016/j.jacc.2012.11.021

52. Risk and Prevention Study Collaborative Group, Roncaglioni MC, Tombesi M, Avanzini F, Barlera S, Caimi V, et al. n-3 fatty acidsin patients with multiple cardiovascular risk factors. N Engl J Med. 2013; 368: $1800-8$

53. Writing Group for the AREDS2 Research Group, Bonds DE, Harrington M, Worrall BB, Bertoni AG, Eaton CB, et al. Effect of long-chain $\omega-3$ fatty acids and lutein + zeaxanthin supplements on cardiovascular outcomes: results of the Age-Related Eye Disease Study 2 (AREDS2) randomized clinical trial. JAMA Intern Med. 2014; 174: 763-71.

54. European Medicines Agency, 6.06.2029, EMA/328211/2019

55. Alexander DD, Miller PE, Van Elswyk ME, Kuratko CN, Bylsma LC. A meta-analysis of randomized controlled trials and prospective cohort studies of eicosapentaenoic and docosahexaenoic long-chain omega-3 fatty acids and coronary heart disease risk. Mayo Clin Proc. 2017; 92: 15-29. doi: 10.1016/j.mayocp.2016.10.018

56. Maki KC, Palacios OM, Bell M, Toth PP. Use of supplemental longchain omega-3 fatty acids and risk for cardiac death: An updated meta-analysis and review of research gaps. J Clin Lipidol. 2017; 11: 1152-1160. doi: 10.1016/j.jacl.2017.07.010

57. Hooper L, Abdelhamid A, Ajabnoor S, Brainard J, Brown T, Hanson, et al. World Health Organization; et al. Set of Systematic Reviews of RCTs on the Health Effects of Omega 3 Polyunsaturated Fats in Adults. Available online: http://www.iffo.net/system/files/WHO\%20 NUGAG_RCTs_report\%20abridged\%20Aug\%202017

58. Aung T, Halsey J, Kromhout D, Gerstein H.C, Marchioli R, Tavazzi L, et al. Associations of omega-3 fatty acid supplement use with cardiovascular disease risks: Meta-analysis of 10 trials involving 77,917 individuals. JAMA Cardiol. 2018; 3: 224-234. doi: 10.1001/ jamacardio.2017.5205
59. Abdelhamid AS, Brown TJ, Brainard JS, Biswas P, Thorpe GC, Moore $\mathrm{HJ}$, et al. Omega- 3 fatty acids for the primary and secondary prevention of cardiovascular disease. Cochrane Database Syst Rev. 2018 Nov 30; 11: CD003177. doi: 10.1002/14651858.CD00317

60. Marston NA, Giugliano RP, Im K, Silverman MG, O'Donoghue ML, Wiviott SD, Ference BA, Sabatine MS. Association Between Triglyceride Lowering and Reduction of Cardiovascular Risk Across Multiple Lipid-Lowering Therapeutic Classes: A Systematic Review and Meta-Regression Analysis of Randomized Controlled Trials. Circulation. 2019 Oct 15; 140(16): 1308-1317. doi: 10.1161/ CIRCULATIONAHA.119.041998

61. Casula M, Olmastroni E, Gazzotti M, Galimberti F, Zambon A, Catapano AL. Omega-3 polyunsaturated fatty acids supplementation and cardiovascular outcomes: do formulation, dosage, and baseline cardiovascular risk matter? An updated meta-analysis of randomized controlled trias. Pharmacol Res. 2020 Jul 4; 160: 105060. doi: 10.1016/j. phrs.2020.105060

62. https://www.fda.gov/news-events/press-announcements/fda-approvesuse-drug-reduce-risk-cardiovascular-events-certain-adult-patientgroups

63. Lombardi M, Chiabrando JG, Vescovo GM, Bressi E, Del Buono MG, Carbone S, et al. Impact of Different Doses of Omega-3 Fatty Acids on Cardiovascular Outcomes: a Pairwise and Network Meta-analysis Curr Atheroscler Rep. 2020 Jul 16; 22(9): 45. doi: 10.1007/s11883-020-00865-5

64. Hilleman DE, Wiggins BS, Bottorff MB. Critical differences between dietary supplement and prescription omega-3 fatty acids: a narrative review. Adv Ther. 2020; 37(2): 656-670. doi: 10.1007/s12325-019-01211-1

65. Chen C, Yu X, Shao S. Effects of omega-3 fatty acid supplementation on glucose control and lipid levels in type 2 diabetes: a meta-analysis. PLoS One. 2015; 10: e0139565. doi: 10.1371/journal.pone.0139565

66. Rimm EB, Appel LJ, Chiuve SE, Djoussé L, Engler MB, Kris-Etherton PM, et al. American Heart Association Nutrition Committee on the Council on Lifestyle and Cardiometabolic Health; et al. Seafood longchain $\mathrm{n}-3$ polyunsaturated fatty acids andcardiovascular disease: A science advisory from the American Heart Association. Circulation 2018; 138(1): e35-e47. doi: 10.1161/CIR.0000000000000574 